\title{
Um bom caminho para adentrar a Psicologia Social ${ }^{12}$
}

\author{
Sandra Souza da Silva Chaves \\ Livia de Oliveira Borges \\ Universidade Federal do Rio Grande do Norte
}

$\mathrm{O}$ livro Psicología social: perspectivas psicológicas e sociológicas, de autoria de José Luis Alvaro e Alicia Garrido, apresenta-se como um imprescindível referencial histórico na compreensão da origem da Psicologia Social até chegar aos ditames teóricos e metodológicos dessa disciplina atualmente. Abrange uma "Introdução" e cinco capítulos, cujos conteúdos obedecem à evolução contextual da Psicologia Social, além de constar de um resumo ao final de cada um. Na organização do livro, os autores chamam a atenção do leitor para os principais teóricos, sejam da Psicologia sejam da Sociologia, de acordo com o tema estudado em questão, separando um tópico dedicado ao trabalho desses autores, destacados à parte do texto principal.

Na introdução, os autores anunciam a idéia central desenvolvida em todo o livro, expondo que o seu principal objetivo é mostrar como a Psicologia Social surgiu, identificando as principais teorias que têm dado corpo a essa ciência, contextualizando o seu desenvolvimento de forma paralela dentro da Psicologia e da Sociologia. Compreendem que as fundamentações em ambas as disciplinas são complementares e não excludentes. Outro objetivo sinalizado pelos autores consiste em reivindicar a importância de alguns teóricos da Sociologia no desenvolvimento das correntes psicossociológicas, objetivando trazer ao âmbito das discussões da Psicologia Social, não apenas as contribuições teóricas da disciplina Psicologia, mas igualmente da Sociologia.

Para atender a tais objetivos, os autores discutem de maneira detalhada as perspectivas epistemológicas e metodológicas que predominavam em cada período histórico analisado, visto que o desenvolvimento da Psicologia Social articula-se aos avanços das demais disciplinas. Para se compreender o pluralismo metodológico que esteve e que se faz presente nos estudos sociais, os autores resgatam as múltiplas influências epistemológicas desde o positivismo em sua versão original até chegar aos diferentes aspectos do positivismo lógico.

Cada capítulo foi organizado de forma que contém uma descrição das concepções da ciência dominante no período indicado, seguida das características centrais do desenvolvimento da Psicologia Social dentro dos referenciais da Psicologia e da Sociologia e, por fim, dedica-se a atenção ao desenvolvimento metodológico da Psicologia Social.

No primeiro capítulo do livro - "As origens do pensamento psicossociológico na segunda metade do século XIX" - os autores descrevem o período em que tanto a Psicologia quanto a Sociologia começaram a se firmar como disciplinas científicas independentes da Filosofia. Foi na Alemanha que a Psicologia se consolidou como uma disciplina independente, sendo, nessa fase, de fundamental importância as contribuições de Wundt, o qual propôs um novo campo de trabalho para a Psicologia que até então se restringia à Psicologia Filosófica no estudo da alma. A partir de Wundt, o estudo da mente, mais acessível dentro dos pressupostos do positivismo, tornou-se o foco principal. A Sociologia, por sua vez, apresentou-se como uma disciplina independente na França, especificamente com o trabalho de Durkheim. A partir de então, essa ciência passou a dedicarse aos fenômenos sociais, os quais deveriam ser considerados como objetivos e externos aos sociólogos.

Os autores seguem trazendo historicamente os principais teóricos das duas disciplinas, mas também não deixam de se referir à importância que a Grã-Bretanha teve no desenvolvimento da Psicologia e das demais Ciências Sociais, mesmo admitindo não haver nenhum autor britânico que concretamente tenha desenvolvido uma teoria psicossociológica. Destacam, entretanto, a influência das idéias da teoria da evolução de Charles Darwin e a lei do uso e desuso de Lamarck. Na Psicologia Social, essas idéias foram introduzidas por Herbert Spencer, ao apresentar uma teoria psicológica evolucionista incluindo noções como a sobrevivência dos mais aptos e de evolução da mente. As idéias de Spencer também foram decisivas no desenvolvimento da sociologia americana.

No segundo capítulo - "A consolidação da Psicologia Social como disciplina independente" - os autores analisam o processo indicado no título a partir das primeiras décadas do século XX. Pontuam as principais correntes da Psicologia na Alemanha, como, a Psicologia da 
Gestalt, cuja influência se fez marcante na Psicologia Social, sendo Kurt Lewin seu principal representante. Também são trazidas algumas considerações sobre as contribuições da teoria psicanalítica para o desenvolvimento das ciências sociais.

No início do século XX, a idéia de que boa parte do comportamento humano é instintiva instigou a Psicologia Social. Essa idéia foi alvo de muitas críticas, até deixar de ser considerada, o que levou a Psicologia a entrar numa nova fase de investigação - as idéias ambientalistas. As teorias do condutismo adquiriram destaque com os trabalhos de Floyd Allport. Foi nesse período em que foram publicados os primeiros manuais de Psicologia tanto na perspectiva psicológica quanto na perspectiva sociológica. Em referência a esta última perspectiva, a Escola de Chicago foi de fundamental importância, destacando-se WilliamThomas e George Mead como representantes. Nesse período, o pragmatismo foi uma forte influência, contribuindo para o surgimento das bases do interacionismo simbólico, principal corrente da Psicologia Social sociológica.

$\mathrm{Na}$ parte dedicada aos pressupostos metodológicos da Psicologia Social, os autores analisam a tendência positivista que se fez presente na consolidação da Psicologia Social como disciplina independente entre as duas perspectivas já citadas. Na perspectiva psicológica, a experimentação foi o método que foi facilmente assimilado, herdado da própria Psicologia que desde o início se inspirou nos métodos da física. Na perspectiva sociológica, influenciados pela Escola de Chicago, predominou o pragmatismo e os sociólogos não utilizavam os métodos da física, mas apenas a investigação naturalista da Biologia.

O terceiro capítulo - “A evolução da Psicologia Social como disciplina científica independente” - avança em relação ao capítulo anterior, pois que especifica o desenvolvimento teórico e metodológico dessa disciplina da década de 1930 até a década de 1940. A princípio influenciada pelo positivismo, a Psicologia aceitou em definitivo a tese da unidade da ciência, em que não havia diferença entre as ciências naturais e as ciências sociais.

Por volta desse período, a Psicologia Social esteve mais voltada a uma perspectiva psicológica, visto que esta atendia melhor às exigências da cientificidade da época, fato esse associado também à crise da Escola de Chicago. Foi, pois, com a Sociologia do Conhecimento que os pressupostos básicos do positivismo passaram a ser questionados. Karl Mannheim propôs o desenvolvimento dessa Sociologia por acreditar que existem formas de pensamento impossíveis de compreensão se as suas origens sociais não estiverem claras, Nesse capítulo ainda é abordada a questão das principais correntes teóricas que melhor se ajustavam aos princípios neopositivistas, como o condutismo (ou behaviorismo) e o neocondutismo (ou neobehaviorismo) que, após Watson, ganhou destaque até os anos 60. No que se refere à Sociologia, a teoria do interacionismo simbólico teve desenvolvimento mais lento, dando lugar à outra teoria - o funcionalismo estrutural - que atendia melhor às exigências da cientificidade da época.

No que diz respeito ao desenvolvimento metodológico dessa fase, os autores conduzem o leitor a compreender a importância que o neopositivismo teve nessa fase, fazendo com que houvesse a intensificação da tendência experimentalista. Mas os autores não deixam de apontar as duas formas distintas para se compreender a experimentação nas ciências sociais. A primeira foi representada pelos neocondutistas e gestaltistas e a segunda, por teóricos mais flexíveis em termos da aplicação do método. A investigação empírica das atitudes teve um forte impulso nessa fase, contribuindo para o crescimento das investigações quantitativas.

Os autores iniciam o quarto capítulo - “A evolução da Psicologia Social até os anos 70”-, descrevendo o avanço da Psicologia Social norte-americana devido à migração dos psicólogos europeus para aquele país, fugindo do nazismo e da II Guerra Mundial. No campo da Sociologia, o funcionalismo estrutural foi o principal modelo teórico dos anos 50 e 60, entrando em crise apenas nos meados dessa última década. Nesse período começaram a surgir teorias alternativas, como as teorias de intercâmbio. Outro importante modelo dentro da Sociologia foi o interacionismo simbólico, o qual tem como um pressuposto essencial a idéia de que a pessoa é o agente de seus próprios atos e o conceito de interação assume um papel central.

No que se refere ao desenvolvimento metodológico da Psicologia Social, os autores argumentam e explicam de forma detalhada o fato de que essa disciplina foi consolidada em uma fase eminentemente experimental. Outrossim, foi no campo da Psicologia Social sociológica que a investigação qualitativa e os estudos de campo tiveram maior influência, observando nessa perspectiva uma maior pluralidade metodológica.

No último capítulo do livro - "A psicologia social atual” - os autores dão uma ênfase maior às mudanças ocorridas no âmbito das ciências de um modo geral com o esmorecimento do positivismo lógico, especificamente, na década de 70, passando a uma reorientação dos estudos em direção aos processos cognitivos. Paralela a essa questão, os autores explicitam de forma clara como foram surgindo propostas tanto teóricas quanto metodológicas na formação de uma nova Psicologia Social. Ainda nesse tópico, são abordados as características principais da Psicologia Social pós-moderna e o seu relativismo epistemológico.

Na parte final desse capítulo, ao falar do desenvolvimento metodológico da Psicologia Social atual, os autores discutem primeiro as críticas em torno da experimentação; posteriormente, se detêm na polêmica em torno da 
metodologia quantitativa e qualitativa e assinalam a crescente superação dessa dicotomia entre os estudiosos, à medida que a adoção de uma postura metodológica que possibilita a articulação de ambas as perspectivas tem se tornado pertinente à obtenção de um adequado conhecimento substantivo sobre a realidade social.

Em síntese, os capítulos estão divididos de forma bastante didática, obedecendo a uma seqüência lógica, oferecendo ao leitor uma visão integrativa dessa disciplina e trazendo os principais questionamentos da área bem como as principais teorias.
A obra contribui efetivamente para a compreensão do que seja a Psicologia Social por meio da análise crítica dos autores sobre o desenvolvimento dessa disciplina a partir de suas duas principais fontes: a perspectiva psicológica e a sociológica. Tal contribuição e a fluente articulação das idéias fazem com que este livro seja um instrumento valioso para os estudiosos da área ou de disciplinas afins, tornando-se um instigante manual, cuja leitura se mostra obrigatória para todos aqueles que desejam se aprofundar no desenvolvimento histórico da Psicologia Social.

1. Resenha do livro Psicología Social: perspectivas psicológicas e sociológicas, de autoria de José Luis Alvaro \& Alicia Garrido, publicado em 2003, em Madri, pela Editora McGraw Hill.

2. Uma edição brasileira se encontra em preparação e deverá estar publicada em meados do próximo ano.

Sandra Souza da Silva Chaves é mestre em Psicologia Social pela Universidade Federal Paraíba e doutoranda em Psicologia Social pelo Programa Integrado de Psicologia Social da Universidade Federal do Rio Grande do Norte e Universidade Federal da Paraíba. E-mail: sandrachaves@yahoo.com.br

Livia de Oliveira Borges, doutora em Psicologia pela Universidade de Brasília, é professora na Universidade Federal do Rio Grande do Norte e bolsista de produtividade em pesquisa do CNPq. E-mail: liviadeoliveira@gmail.com

Endereço para correspondência: Departamento de Psicologia; Centro de Ciências Humanas, Letras e Artes; Universidade Federal do Rio Grande do Norte; Campus Universitário, s/n, Capim Macio; Natal, RN. 